\title{
Determining the Acute Toxicity of New Preparation Vetom 20.76 on Geese and Ducks
}

\section{Grigory Antonovich Nozdrin ${ }^{1 *}$, Regina Gabdrahmanovna Utkina ${ }^{2}$, Anastasia Aleksandrovna Lelyak ${ }^{2}$ and Yana Viktorovna Novik ${ }^{1}$}

${ }^{1}$ Department of Pharmacology and General Pathology, Faculty of Veterinary Medicine, Novosibirsk State Agrarian University, Dobrolubova 160, Novosibirsk, Russian Federation; ${ }^{2}$ Faculty of Veterinary Medicine, Novosibirsk State Agrarian University, Dobrolubova 160, Novosibirsk, Russian Federation.

\begin{abstract}
The current study aim to investigate the acute toxicity of the new microbial preparation from a predatory fungus Arthrobotrys oligospora in birds. The experiments were performed on two-days-old goslings and ducklings which were divided into four experimental groups and a reference group. The fowls in experimental groups were supplemented with preparation once with dosages $(2,000 \mu 1 / \mathrm{kg}, 3,000 \mu 1 / \mathrm{kg}, 4,000$ $\mu \mathrm{l} / \mathrm{kg}$, and $5,000 \mathrm{ml} / \mathrm{kg}$ ) while the fowl in the reference group were left untreated (they were given a placebo - distilled water). The experimental fowl were monitored every hour during the first day, and every day afterward for a total of 14 days. The live body weight was measured every week; the overall condition of the fowl, behavior, physical activity, water, and feed consumption were monitored. At the end of the experiment, autopsy and morphometry of internal organs were assessed. No toxic effect of the experimental sample (Vetom 20.76) was observed during the experiment. The fowl in the experimental groups had positive dynamics on the weight gain, growth, and development even at the dosage of the preparation of $5,000 \mu \mathrm{l} / \mathrm{kg}$. During the general autopsy, no pathologic changes of internal organs were observed in the fowl in the experimental groups. At the end of the research, Vetom 20.76 was classified as a substance of Toxic Class 4 according to GOST 12.1.007-76 Occupational safety standards system, 1976.

Received | September 30, 2019; Accepted | March 13, 2020; Published | April 25, 2020

*Correspondence | Grigory Antonovich Nozdrin, Department of Pharmacology and General Pathology, Faculty of Veterinary Medicine, Novosibirsk State Agrarian University, Dobrolubova 160, Novosibirsk, Russian Federation; Email: vrsunlight@list.ru

Citation | Nozdrin, G.A., R.G. Utkina, A.A. Lelyak and Y.V. Novik. 2020. Determining the acute toxicity of new preparation vetom 20.76 on geese and ducks. Sarhad Journal of Agriculture, 36(2): 470-477.

DOI | http://dx.doi.org/10.17582/journal.sja/2020/36.2.470.477

Keywords | Acute toxicity, Preclinical studies, Vetom, Arthrobotrys oligospora, Vetom 20.76
\end{abstract}

\section{Introduction}

$\mathrm{O}$ wing to high (46\%) dependency of the agroindustrial complex of the Russian Federation on livestock production, increasing the livestock preservation and productivity rates is a priority task of modern livestock breeding (Baranikov et al., 2017; Donnik et al., 2015). The chemotherapeutic medicinal products used at livestock breeding farms do not always have the desired effects, as they have many side effects. The use of most chemotherapeutic products results in decreasing the quality of the livestock product. Therefore, an alternative way of resolving these problems, according to most domestic (Nozdrin et al., 2017; Teplyakova, 2018) and foreign researchers (Morgan et al., 1997) is the use of biologically active medicinal products. The biologically active medicinal products that are organic and physiological for the livestock possess rather efficient therapeutic, preventive and growth-promoting actions (Aldobaeva, 2016; Nozdrin and Shevchenko, 2006; Nozdrin et al., 2017; Pyshmantseva et al., 2011; Salkova et al., 
2014; Uchasov et al., 2014; Feoktistova et al., 2017). Therefore, modern veterinary pharmacology attracts considerable attention in creating environmentally safe preparations with an efficient pharmacological action. The efficient biological material for creating such preparations may be cultures of predatory fungi (Perez et al., 2017; Santos et al., 2001; Shkolnikov et al., 2014).

The nematophagous fungi have been used for over a hundred years in crops cultivation for combating root-knot nematode, sugar beet nematode, potato nematode, etc. (Duddington, 1959). However, modern studies have showed that these soil saprophytes can possess predatory activity not only for the soil nematodes but also against the nematodes in animals. The strain Duddingtonia flagrans IAH 1297 bred in Australia can live on pastures, or in manure, where it creates a microscopic mesh that parasites on and consumes the juvenile stages of parasitic worms. Since it possesses high specificity, it aims only at the parasitic nematodes in farm animals (Duddingtonia, n.d.). This process is only possible under the condition that the animals are fed with chlamydospores Duddingtonia flagrans IAH 1297, after which they are excreted with the feces, and get activated when the larvae of parasitic worms become active (Perez et al., 2017; Duddingtonia, n.d.).

In the studies performed by the Mexican scientists, it has been found that the use of chlamydospores Duddingtonia flagrans reduces the number of larvae of such genera such as Strongyloides sp., Haemonchus sp. Cooperia sp., Trichostrongylus sp., Oesophagostomum sp., and Mecistocirrus sp. in the feces of cattle by 53.8 $\%$, compared to the reference groups (Perez et al., 2017). At the same time, the Australian scientists who have been studying Duddingtonia flagrans for 10 years state that the number of parasitic larvae in the feces of cattle decreases by 75-88 \% (average $81 \%$ ), respectively (Duddingtonia, n.d.).

According to the Chinese scientists, the sticky loops of the fungi of genus Arthrobotrys oligospora reduce the number of larvae and eggs of trichostrongyles (such as Trichostrongylus colubriformis and Haemonchus contortus) by 90-99 \%, respectively (Cai et al., 2017). Besides, there is evidence of the ability of Arthrobotrys oligospora to show predatory activity against Strongyloides ssp. (Bird and Herd, 1995; Chandrawathani et al., 1998), Haemonchus contortus (Gutierrez et al., 2011; Wang et al., 2014), Heligmosomoides polygyrus (Morgan et al., 1997), and Ostertagia ostertagi (Dackman and Nordbring-Hertz, 1992).

The Novosibirsk scientists have identified two species of predatory fungi Artbrobotrys oligospora BKMF-3062 L and Duddingtonia flagrans T-89, which manifest predatory properties against rootknot nematodes in plant and parasitic nematodes in animals. The characteristics of these species are their high efficiency in the destruction of rootknot nematodes in plants, pathogens of helminths in animals, and the ability to remain viable without the loss of properties, both when passing through the gastrointestinal tract of animals and in the soil conditions (RF patent No. 2253671, 1998).

The current research was set up to study the acute toxicity of the new microbiological preparation Vetom 20.76 on geese and ducks.

\section{Materials and Methods}

The object of the research was experimental preparation of Vetom 20.76, developed at LLC Scientific-Production Company Research Center (country?). The acute toxicity was studied according to GOST R 54063-2010 Medicine remedies for veterinary use. Methods of safety identification.

The toxicity studies were performed on goslings (of the Linda breed) and ducklings (of the Favorite breed). In the experiment, two-days-old fowl of both genders were used, with the average body mass of $105.2 \mathrm{~g}$ for goslings, and the average body weight of $51.42 \mathrm{~g}$ for ducklings. The difference in the body weight of the experimental fowl was less than \pm 10 $\%$. For studying the acute toxicity to the principle of analogous pairs, four experimental and one reference groups were formed, each carrying six ducklings. The experimental groups of goslings were formed in the same way. The preparation was administered before feeding the fowl. The ducklings in the first experimental group received the preparation once at the dosage of $2,000 \mu \mathrm{l}$, in the second experimental group at the dosage of $3,000 \mu \mathrm{l}$, in the third group at the dosage of $4,000 \mu 1$, and in the fourth group at the dosage of $5,000 \mu \mathrm{l}$ per one kilogram of the live weight. The ducklings in the reference group received placebo, which means weren't administered the actual preparation. The goslings in the experimental and 
reference groups received the studied preparation in the same way.

The fowl were observed individually after the introduction of the dosage for not less than one time in the first 30 minutes, the first hour, the first four hours, in the first 12 hours, and afterward every day for 14 days.

During the observation, the changes in the overall state of the fowl were taken into account, along with the peculiarities of their behavior, the intensity and the nature of their locomotor activity, the presence and the nature of seizures, the coordination of movement, the tone of the skeletal muscles, the reaction to the tactile, pain, sound, and light irritants, the frequency and the depth of the respiratory movements, the heart rate, the color of the mucous membranes, the consistency of fecal masses, the consumption of the feed and water, and the changes in the body weight. The changes in the behavior (excitation or inhibition) were registered using a scoring system. The fowl were weighed before the introduction of the preparation, and once a week for 14 days of the experiment. On the 14th day of the experiment, all fowl were killed humanely and subjected to autopsy. At the end of the experiment, the toxicity class of the studied preparation was determined according to GOST 12.1.007 (cite a reference here).

\section{Results and Discussion}

After a single introduction of the studied preparation, after 30 minutes, one, four, and six hours of observation, the authors did not find any pathological changes in the overall state of the experimental fowl. Within the next 14 days of observation of goslings and ducklings, no negative changes in the overall physiological state were found. In the experimental and the reference groups, no deaths of the fowl were noted. In the experimental groups, an increased consumption of the feed and water was observed.

No deviations in the development of the fowl in the experimental and the reference groups were noted. The locomotor activity of ducklings and goslings was positive. No seizures or involuntary movements were noted in the experimental groups. The reaction of the fowl to the pain, tactile, sound, and light irritants was preserved. The heart and the respiratory rate remained within the physiological normal. The consistency of fecal masses corresponded to the species-related characteristics of waterfowl.

Over the entire duration of the experiment, the weight of the fowl increased within the limits of the age norms for ducks and geese (Tables 1 and 2).

Table 1: Changes in the live weight of the experimental ducklings, $g$.

\begin{tabular}{|c|c|c|c|}
\hline \multicolumn{2}{|c|}{ Dosage $\mu 1 / \mathbf{k g}$ Group } & $n \overline{\mathbf{X}}_{ \pm \mu}$ & $\mathbf{C v}$ \\
\hline \multicolumn{4}{|c|}{ Before the experiment } \\
\hline 2,000 & First experimental & $651.46 \pm 0.22$ & 0.94 \\
\hline 3,000 & Second experimental & $651.37 \pm 0.22$ & 0.97 \\
\hline 4,000 & Third experimental & $651.15 \pm 0.28$ & 1.24 \\
\hline 5,000 & Fourth experimental & $651.38 \pm 0.19$ & 0.85 \\
\hline- & Reference & $652.05 \pm 0.16$ & 0.67 \\
\hline \multicolumn{4}{|c|}{7 days of testing the preparation } \\
\hline- & First experimental & $6 \quad 268.17 \pm 7.16$ & 5.97 \\
\hline- & Second experimental & $6269.67 \pm 4.69$ & 3.89 \\
\hline- & Third experimental & $6267.50 \pm 1.67$ & 1.39 \\
\hline- & Fourth experimental & $6 \quad 274.50 \pm 3.56$ & 2.90 \\
\hline- & Reference & $6 \quad 263.33 \pm 1.74$ & 1.47 \\
\hline
\end{tabular}

14 days of testing the preparation

First experimental $6 \quad 694.33 \pm 4.16 \quad 1.57$

Second experimental $6 \quad 607.00 \pm 5.97 \quad 2.20$

Third experimental $6 \quad 600.50 \pm 3.11 \quad 1.16$

Fourth experimental $6 \quad 612.33 \pm 3.43^{* *} 1.25$

Reference $\quad 6 \quad 582.17 \pm 4.78 \quad 2.14$

The statistically significant difference from the reference: $*-P<0.05$; ** $-P<0.01$.

On the seventh day of the experiment, the ducklings in experimental groups 1 through 4 , compared to the reference, had the following live weight gain: by $1.8 \%$ in the first group, by $2.35 \%$ in the second group, by $1.55 \%$ in the third group, and by $4.06 \%$ in the fourth group. After 14 days, in the experimental groups an increase in the live weight gain was observed, compared to the reference, by $2.06 \%$ in the first group, by $4.09 \%$ in the second group, by $3.05 \%$ in the third group, and by $4.92 \%$ in the fourth group (P $<0.01$ ) (Table 1).

Based on the data in Table 2, compared to the reference, on the seventh day of the experiment, an increase in the life weight gain was observed by $0.51 \%$ in the first experimental group, by $3.75 \%$ in the second experimental group, by $1.56 \%$ in the third group, and by $4.67 \%$ in the fourth experimental group. After 14 
days, in the experimental groups an increase in the live weight gain of the geese was observed, compared to the reference, by $0.83 \%$ in the first group, by $2.2 \%$ in the second group, by $0.72 \%$ in the third group, and by $3.16 \%$ in the fourth group $(\mathrm{P}<0.01)$ (Table 1$)$.

Table 2: Changes in the live weight of the experimental goslings, $g$ :

\begin{tabular}{|c|c|c|c|c|}
\hline \multicolumn{2}{|c|}{ Dosage $\mu 1 / \mathrm{kg}$ Group } & $\mathbf{n}$ & $\overline{\mathbf{X}}_{ \pm \mu}$ & $\mathrm{Cv}, \%$ \\
\hline \multicolumn{5}{|c|}{ Before the experiment } \\
\hline 2,000 & First experimental & 6 & $104.00 \pm 2.10$ & 4.51 \\
\hline 3,000 & Second experimental & 6 & $104.5 \pm 1.99$ & 4.27 \\
\hline 4,000 & Third experimental & 6 & $105.33 \pm 1.97$ & 4.19 \\
\hline 5,000 & Fourth experimental & 6 & $105.67 \pm 2.07$ & 4.38 \\
\hline - & Reference & 6 & $106.17 \pm 2.09$ & 4.39 \\
\hline
\end{tabular}

7 days of testing the preparation

$\begin{array}{llrrr}- & \text { First experimental } & 6 & 326.50 \pm 8.11 & 5.56 \\ - & \text { Second experimental } & 6 & 337.50 \pm 9.26 & 6.13 \\ - & \text { Third experimental } & 6 & 330.00 \pm 5.49 & 3.72 \\ - & \text { Fourth experimental } & 6 & 340.67 \pm 7.68 & 5.04 \\ - & \text { Reference } & 6 & 324.83 \pm 5.77 & 3.97\end{array}$

14 days of testing the preparation

First experimental $\quad \begin{array}{lll}6 & 781.00 \pm 6.84 & 1.96\end{array}$

Second experimental $6 \quad 792.00 \pm 4.73 \quad 1.34$

Third experimental $\quad 6 \quad 780.17 \pm 3.24 \quad 0.93$

Fourth experimental $6 \quad 799.83 \pm 3.15^{\text {** }} 0.88$

Reference $\quad 6 \quad 774.50 \pm 5.96 \quad 1.72$

The statistically significant difference from the reference: $*-P<0.05$; ** $-P<0.01$

The macroscopic examination did not reveal a pathologic picture of poisoning: the position of the internal organs in the thoracic and the abdominal cavities was anatomically correct, the color and the texture of the organs had not changed (Figures 1, 2 and 3).
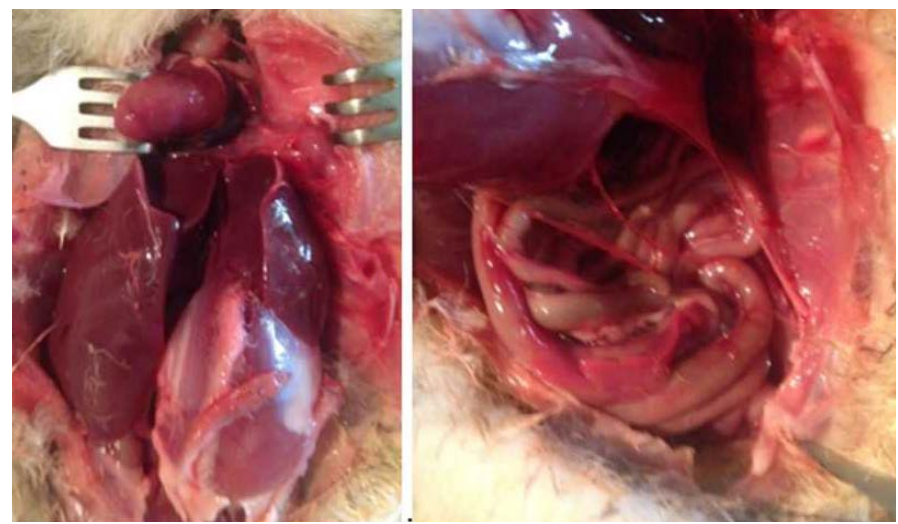

Figure 1: Autopsy

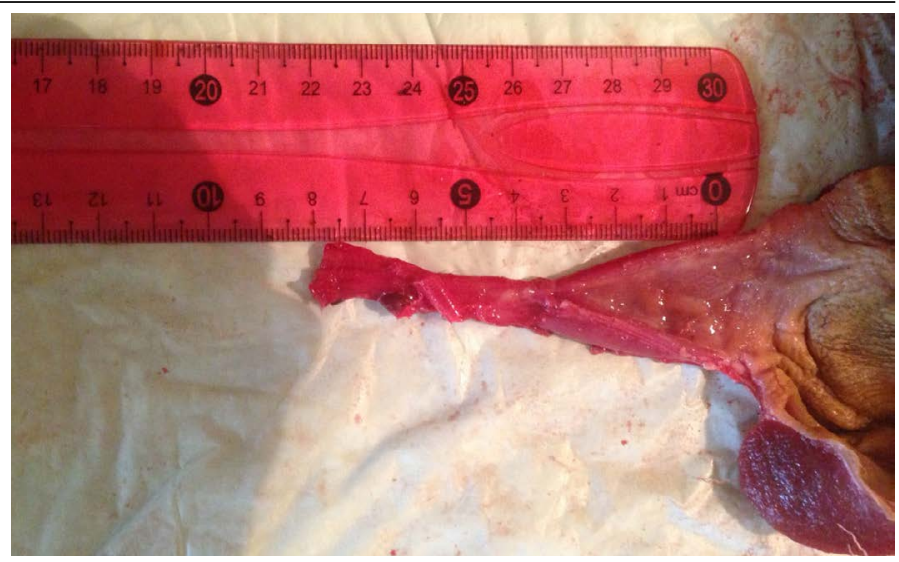

Figure 2: Proventriculus

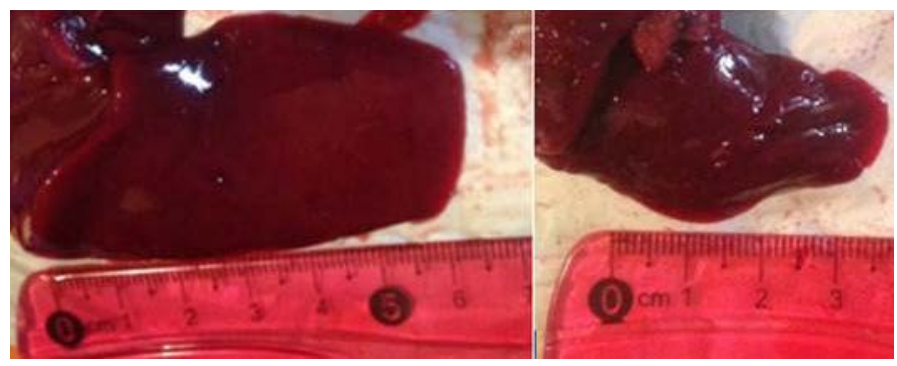

Figure 3: Liver

The morphometric values of the weight of the organs of the experimental fowl in groups 1 through 4 and in the reference group were within the physiological norm. The results of the morphometric study of the internal organs are shown in Tables 3 and 4.

Based on the data from Table 3, the weight of the heart in the experimental fowl was higher than that in the reference group by $2.0 \%$ in the first group, by $4.21 \%$ in the second group, by $3.6 \%$ in the third group, and by $5.0 \%$ in the fourth group $(\mathrm{P}<0.05)$. By the weight of the lungs, the experimental groups exceeded the reference group by $0.91 \%$ in the first group, by 3.55 $\%$ in the second group, by $2.39 \%$ in the third group, and by $4.82 \%$ in the fourth group, respectively. By the weight of the liver, the experimental groups exceeded the reference group by $3.91 \%$ in the first group, by $4.85 \%$ in the second group, by $6.18 \%$ in the third group, and by $7.52 \%$ in the fourth group $(\mathrm{P}<0.01)$. By the weight of the proventriculus, the experimental groups exceeded the reference group by $1.21 \%$ in the first group, by $4.12 \%$ in the second group, by $2.4 \%$ in the third group, and by $4.69 \%$ in the fourth group. By the weight of the gizzard, the experimental groups exceeded the reference group by $2.0 \%$ in the first group, by $4.10 \%$ in the second group, by $3.82 \%$ in the third group, and by $5.01 \%$ in the fourth group $(\mathrm{P}<$ 0.01). By the weight of the intestine, the experimental groups exceeded the reference group by $1.20 \%$ in the

June 2020 | Volume 36 | Issue 2 | Page 473 
Table 3: The weight of the internal organs of the experimental ducklings, $g$.

Indicators

Groups in the experiment

First experimental Second experimental Third experimental Fourth experimental

$\begin{array}{lllllllllll} & \overline{\mathbf{X}} \pm \boldsymbol{\mu} & \mathbf{C v}, \boldsymbol{\%} & \overline{\mathbf{X}} \pm \boldsymbol{\mu} & \mathbf{C v}, \boldsymbol{\%} & \overline{\mathbf{X}} \pm \boldsymbol{\mu} & \mathbf{C v}, \boldsymbol{\%} & \overline{\mathbf{X}} \pm \boldsymbol{\mu} & \mathbf{C v}, \boldsymbol{\%} \overline{\mathbf{X}} \pm \boldsymbol{\mu} & \mathbf{C v}, \boldsymbol{\%} \\ \text { Heart } & 7.65 \pm 0.07 & 3.78 & 7.82 \pm 0.19 & 5.37 & 7.77 \pm 0.12 & 2.22 & 7.89 \pm 0.12^{*} & 3.21 & 7.49 \pm 0.06 & 1.88 \\ \text { Lungs } & 6.57 \pm 0.17 & 5.72 & 6.75 \pm 0.06 & 2.01 & 6.67 \pm 0.12 & 4.14 & 6.84 \pm 0.11 & 3.67 & 6.51 \pm 0.13 & 4.37 \\ \text { Liver } & 16.11 \pm 0.14 & 1.99 & 16.27 \pm 0.29 & 4.05 & 16.50 \pm 0.15 & 2.04 & 16.74 \pm 0.16^{* *} & 2.13 & 15.48 \pm 0.16 & 2.24 \\ \text { Proventriculus } & 3.29 \pm 0.07 & 5.02 & 3.39 \pm 0.11 & 7.43 & 3.33- \pm 0.07 & 4.81 & 3.41 \pm 0.1 & 6.33 & 3.25 \pm 0.1 & 6.86 \\ \text { Gizzard } & 23.37 \pm 0.32 & 3.08 & 23.86 \pm 0.45 & 4.22 & 23.79 \pm 0.34 & 3.18 & 24.11 \pm 0.17 * * & 1.55 & 22.88 \pm 0.3 & 2.88 \\ \text { Intestine } & 29.76 \pm 0.7 & 5.28 & 30.98 \pm 1.81 & 13.04 & 30.95 \pm 2.26 & 16.34 & 30.66 \pm 1.34 & 9.79 & 29.40 \pm 1.63 & 12.40 \\ \text { Kidneys } & 2.37 \pm 0.07 & 6.54 & 2.44 \pm 0.05 & 4.91 & 2.42 \pm 0.06 & 5.39 & 2.46 \pm 0.06 & 5.61 & 2.34 \pm 0.04 & 3.68 \\ \text { Brain } & 3.41 \pm 0.03 & 2.27 & 3.46 \pm 0.04 & 2.83 & 3.47 \pm 0.01 & 0.76 & 3.51 \pm 0.04 & 2.55 & 3.33 \pm 0.04 & 2.71\end{array}$

The statistically significant difference from the reference: ${ }^{*}-P<0.05 ; * *-P<0.01$.

Table 4: The weight of the internal organs of the experimental goslings, $g$.

Indicators

Groups in the experiment

First experimental Second experimental Third experimental

$\begin{array}{llllll}\overline{\mathbf{X}} \pm \mu & \mathrm{Cv}, \% & \overline{\mathbf{X}} \pm \mu & \mathrm{Cv}, \% & \overline{\mathbf{X}} \pm \mu & \mathrm{Cv}, \%\end{array}$

Heart

$10.16 \pm 0.091 .94$

$10.36 \pm 0.112 .46$

$10.30 \pm 0.132 .79$

Lungs

$9.09 \pm 0.09 \quad 2.18$

$9.20 \pm 0.07 \quad 1.75$

$9.07 \pm 0.12 \quad 2.89$

Liver

$36.54 \pm 1.046 .39$

$37.15 \pm 0.55 \quad 3.34$

$37.02 \pm 1.08 \quad 6.55$

Proventriculus $4.37 \pm 0.07 \quad 3.35$

$4.38 \pm 0.15 \quad 7.51$

$4.29 \pm 0.13 \quad 6.81$

$33.98 \pm 0.151 .02$

$33.50 \pm 0.1 \quad 0.65$

Gizzard

$33.56 \pm 0.28 \quad 1.84$

Intestine

$37.98 \pm 1.046 .14$

$38.81 \pm 0.90 \quad 5.17$

$38.97 \pm 1.28 \quad 7.34$

Kidneys

$2.96 \pm 0.05 \quad 4.01$

$3.09 \pm 0.14 \quad 9.91$

$2.97 \pm 0.12 \quad 8.92$

Brain

$4.43 \pm 0.05 \quad 2.64$

$4.49 \pm 0.05 \quad 2.46$

Fourth experimental

$\overline{\mathbf{X}} \pm \mu \quad \mathrm{Cv}, \%$

Reference

$10.41 \pm 0.091 .88$

$\overline{\mathbf{X}} \pm \mu \quad \mathrm{Cv}, \%$

$9.30 \pm 0.08 \quad 2.04$

$10.04 \pm 0.081 .9$

$9.02 \pm 0.13 \quad 3.14$

$37.43 \pm 1.54 \quad 9.22$

$36.30 \pm 0.996 .11$

$4.50 \pm 0.10 \quad 4.83$

$4.36 \pm 0.16 \quad 8.20$

$34.38 \pm 0.19^{* *} 1.22$

$33.29 \pm 0.291 .93$

$40.18 \pm 0.86 \quad 4.77$

$37.72 \pm 1.217 .18$

$3.18 \pm 0.16 \quad 11.27$

$2.99 \pm 0.09 \quad 6.74$

$4.65 \pm 0.03 \quad 1.64$

The statistically significant difference from the reference: $*-P<0.05 ; * *-P<0.01$.

Table 5: The weight coefficients of the internal organs (the weight of the organ $(g)$ to the total weight $(g)$ ratio) in the ducks.

Indicators

\begin{tabular}{|c|c|c|c|c|c|c|c|c|c|c|}
\hline & \multicolumn{2}{|c|}{ First experimental } & \multicolumn{2}{|c|}{ Second experimental } & \multicolumn{2}{|c|}{ Third experimental } & \multicolumn{2}{|c|}{ Fourth experimental } & \multirow[b]{2}{*}{$\overline{\mathbf{X}} \pm \mu$} & \multirow[b]{2}{*}{$\mathrm{Cv}, \%$} \\
\hline & $\overline{\mathbf{X}} \pm \mu$ & $\mathrm{Cv}, \%$ & $\overline{\mathbf{X}} \pm \mu$ & $\mathrm{Cv}, \%$ & $\overline{\mathbf{X}} \pm \mu$ & $\mathrm{Cv}, \%$ & $\overline{\mathbf{X}} \pm \mu$ & $\mathrm{Cv}, \%$ & & \\
\hline Heart & $1.28 \pm 0.01$ & 2.30 & $1.28 \pm 0.02$ & 4.10 & $1.28 \pm 0.01$ & 2.40 & $1.29 \pm 0.02$ & 2.69 & $1.29 \pm$ & 2.05 \\
\hline Lungs & $1.11 \pm 0.03$ & 5.76 & $1.12 \pm 0.01$ & 0.45 & $1.11 \pm 0.02$ & 3.96 & $1.12 \pm 0.02$ & 3.41 & $1.12 \pm 0.02$ & 3.68 \\
\hline Liver & $2.71 \pm 0.02$ & 1.26 & $2.68 \pm 0.04$ & 3.34 & $2.75 \pm 0.03$ & 2.16 & $2.74 \pm 0.02$ & 1.30 & $2.72 \pm 0.01$ & 0.82 \\
\hline Proventriculus & $0.55 \pm 0.01$ & 4.38 & $0.56 \pm 0.02$ & 7.58 & $0.56 \pm 0.01$ & 4.80 & $0.56 \pm 0.02$ & 6.93 & $0.56 \pm 0.02$ & 7.23 \\
\hline Gizzard & $3.93 \pm 0.05$ & 2.80 & $3.93 \pm 0.06$ & 3.31 & $3.94 \pm 0.05$ & 2.95 & $3.94 \pm 0.03$ & 1.54 & $3.93 \pm 0.06$ & 3.59 \\
\hline Intestine & $5.01 \pm 0.1$ & 4.40 & $5.11 \pm 0.32$ & 13.96 & $5.15 \pm 0.36$ & 15.72 & $5.01 \pm 0.21$ & 9.41 & $5.05 \pm 0.27$ & 11.8 \\
\hline Kidneys & $0.40 \pm 0.01$ & 5.92 & $0.41 \pm 0.01$ & 4.06 & $0.41 \pm 0.01$ & 6.00 & $0.40 \pm 0.01$ & 5.55 & $0.40 \pm 0.01$ & 4.62 \\
\hline Brain & $0.57 \pm 0.01$ & 1.82 & $0.57 \pm 0.01$ & 2.22 & $0.58 \pm 0.01$ & 1.30 & $0.57 \pm 0.01$ & 1.82 & $0.57 \pm 0.01$ & 1.42 \\
\hline
\end{tabular}

first group, by $5.10 \%$ in the second group, by $5.0 \%$ in the third group, and by $4.10 \%$ in the fourth group. By the weight of the kidneys, the experimental groups exceeded the reference group by $1.2 \%$ in the first group, by $4.09 \%$ in the second group, by $3.30 \%$ in the third group, and by $4.87 \%$ in the fourth group. By the weight of the brain, the experimental groups exceeded the reference group by $2.34 \%$ in the first group, by $3.75 \%$ in the second group, by $1.7 \%$ in the third group, and by $5.12 \%$ in the fourth group, respectively. 
Table 6: The weight coefficients of the internal organs (the weight of the organ $(g)$ to the total weight $(g)$ ratio) in the geese.

\section{Indicators}

$\begin{array}{lllll} & \overline{\mathbf{X}} \pm \mu & \mathrm{Cv}, \% & \overline{\mathbf{X}} \pm \mu & \mathrm{Cv}, \% \\ \text { Heart } & 1.30 \pm 0.01 & 0.58 & 1.31 \pm 0.01 & 1.48 \\ \text { Lungs } & 1.17 \pm 0.01 & 2.81 & 1.16 \pm 0.01 & 1.14 \\ \text { Liver } & 4.68 \pm 0.15 & 7.12 & 4.69 \pm 0.08 & 3.70 \\ \text { Proventriculus } & 0.56 \pm 0.01 & 4.66 & 0.55 \pm 0.02 & 7.55 \\ \text { Gizzard } & 4.30 \pm 0.01 & 0.27 & 4.29 \pm 0.01 & 0.37 \\ \text { Intestine } & 4.86 \pm 0.10 & 4.52 & 4.90 \pm 0.11 & 4.83 \\ \text { Kidneys } & 0.38 \pm 0.01 & 3.72 & 0.39 \pm 0.02 & 9.73 \\ \text { Brain } & 0.57 \pm 0.01 & 1.32 & 0.57 \pm 0.01 & 3.09\end{array}$

According to the data in Table 4, the weight of the heart of the experimental geese exceeded that of the geese in the reference group by $1.18 \%$ in the first group, by $3.08 \%$ in the second group, by $2.52 \%$ in the third group, and by $3.55 \%$ in the fourth group. By the weight of the lungs, the experimental groups exceeded the reference group by $0.77 \%$ in the first group, by $1.95 \%$ in the second group, by $0.55 \%$ in the third group, and by $3.01 \%$ in the fourth group. The weight of the liver in the experimental groups exceeded that in the reference group by $0.65 \%$ in the first group, by $2.28 \%$ in the second group, by $1.94 \%$ in the third group, and by $3.01 \%$ in the fourth group. The weight of the proventriculus in the first experimental group exceeded that in the reference group by $0.22 \%$, in the second group by $0.45 \%$, and in the fourth group by $3.11 \%$, respectively. The weight of the gizzard in the experimental groups exceeded the weight of the gizzard in the reference group by $0.80 \%$ in the first group, by $2.03 \%$ in the second group, by $0.62 \%$ in the third group, and by $3.17 \%$ in the fourth group $(\mathrm{P}<$ 0.01). By the weight of the intestine, the experimental groups exceeded the reference group by $0.68 \%$ in the first group, by $2.80 \%$ in the second group, by $3.2 \%$ in the third group, and by $6.12 \%$ in the fourth group. The weight of the kidneys in the experimental groups exceeded that in the reference group by $3.23 \%$ in the second group and by $5.97 \%$ in the fourth group. The weight of the brain in the second experimental group exceeded that in the reference group by $0.89 \%$, in the third group by $1.11 \%$, and in the fourth group by 4.5 $\%$, respectively.

According to the data in Tables 5 and 6, no statistically significant difference was observed between the weight coefficients in the experimental and the reference groups, which is evidence of the absence of toxic effect and target organs.

\section{Conclusions and Recommendations}

No lethal dosage of Vetom 20.76 was observed as no fowl mortality appeared throughout the experiment even when the preparation was used at high dosage of $5,000 \mu \mathrm{l} / \mathrm{kg}$. By the classification of toxicity for pharmacological substances according to GOST 12.1.007-76, the preparation may be attributed to toxicity class 4 . The Vetom 20.76 was physiologically normal for geese and ducks. Throughout the experiment, no disorders in the physiological state of the organisms of the experimental ducklings and goslings was noted. The goslings and ducklings growth intensity was increased and had positive dynamics throughout the experiment. Overall autopsy of the experimental fowl was not revealed any pathological changes. The weight coefficients of the geese and ducks in experimental groups 1 through 4 was not shown to be veracious difference from their analogs in the reference group. The research results can be used in veterinary medicine and poultry farming in order to preserve the genetic health of animals, correct their physiological status and prevent helminth infections.

\section{Novelty statement}

For the first time the acute toxicity of microbiological preparation Vetom 20.76 was studied, its toxicity class was determined along with the effect of this preparation on the physiological state and fowl preservation. The predatory fungus Arthrobotrys oligospora, which is used for producing Vetom 20.76, possessed high resistance to digestive juices and the 
enzymes in the gastrointestinal tract, the fungus does not become part of the normal microflora, and is completely removed from the organism in a week.

Microbiological preparations have a wide spectrum of positive actions. According to Russian researchers (Teplyakova, 1999, 2018; RF patent No. 2253671, 1998; RF patent No. 2634390 S1. 2016), in the mycelium and hunting devices of Arthrobotrys oligospora, silicon, sulfur, phosphorus, potassium and calcium were found. Arthrobotrys oligospora nanoparticles induce the secretion of not only TNF- $\alpha$ (Tumor necrosis factor-alpha), but also IL-6 (Interleukin-6) and G-CSF (Granulocyte-colony stimulating factor). Thus, Arthrobotrys oligospora may be a potential candidate for the development of microbiological preparations capable of supporting the immune status and productivity of animals.

\section{Author's Contribution}

G.A. Nozdrin developed the design and formulated the scientific problem of the research. R.G. Utkina collected data and processed it statistical, interpreted the obtained results, literature review, and writing the main part of the article. A.A. Lelyak and Ya. V. Novik did formation of the scientific apparatus of the research, the relevance of the topic chosen, the problems, the purpose, the object, the subject, the hypothesis, and the tasks.

\section{Conflict of interest}

The authors have declared no conflict of interest.

\section{References}

Aldobaeva, N.A., 2016. (Ispolzovanie novykh effektivnykh preparatov zhivotnovodstve (The use of new efficient preparations in livestock breeding). Online Sci. J. Orel SAU. 2(7): 34-38.

Baranikov, V.A, E.A. Kryshtop, A.N. Baranikova and V.H. Fedorov. 2017. Sostoyanie i problemy razvitiya ptitsevodstva (The state and the problems of poultry farming development). Materials of the All-Russia scientific-practical conference (settlement Persianovsky, Feb. 9, 2017). Don SAU.pp. $39-41$.

Bird,J., and R.P.Herd.1995. In vitro assessment of two species of nematophagous fungi (Arthrobotrys oligospora and Arthrobotrys flagrans) to control the development of infective cyathostome larvae from naturally infected horses. Vet. Parasitol. 56(1-3): 181-187. https://doi.org/10.1016/03044017(94)00663-W

Cai, K.-Z., K.-Y. Wang, F.-H. Wang, K.Y., Liu, J.L., Wang, B.B., Xu, Q. Xue, Y.J., Wang, F., Zhang, C., Fang, W.X., Cai, B., Liu, Y.Q. Cao and Z.R. Ma. 2017. In vitro predatory activity of Arthrobotrys oligospora and after passing through gastrointestinal tract of small ruminants on infective larvae of trichstrongylides. Exp. Parasitol. 177: 74-78. https://doi.org/10.1016/j. exppara.2017.04.008

Chandrawathani, P., J. Omar and P.J. Waller. 1998. The control of the free-living stages of Strongyloides papillosus by the nematophagous fungus, Arthrobotrys oligospora. Vet. Parasitol., 76(4): 321-325. https://doi.org/10.1016/S03044017(97)00170-2

Dackman, C.and B. Nordbring-Hertz.1992.Conidial traps a new survival structure of the nematodetrapping fungus Arthrobotrys oligospora. Mycol. Res., 96(3): 194-198. https://doi.org/10.1016/ S0953-7562(09)80965-9

Donnik, I.M, B.A. Voronin and O.G. Loretz. 2015. Importozameshchenie selskokhozyaistvennoi produktsii, syrya i prodovolstviya: sostoyanie, zadachi (Import substitution of agricultural products, raw materials, and foodstuffs: status, tasks). Agrarian News Urals. 3(133): 54-59.

Duddington, K.L., 1959. Khishchnye griby druzya cheloveka (Predatory fungi friends of the man). Foreign Languages Publ. House, Moscow. pp. 10-16.

Duddingtonia, n.d. Short term efficacy studies with Duddingtonia flagrans (Digital resourse). https:// www.duddingtonia.com/articles/short-termefficacy-studies

Feoktistova, N.V., A.M. Mardanova, G.F. Khadieva and F.M. Rashidovna 2017. Probiotiki na osnove bakterii roda Bacilus subtilis $\mathrm{v}$ ptitsevodstve (Probiotics based on the bacteria of genus Bacilus subtilis in poultry breeding). Sci. Notes Kazan Univ. 159: 85-107.

Gutierrez, I.C.A., P.M. de Gives, E.L. Hernández E.L. Arellano, R.O.V. Coss and V.M.H. Velázquez. 2011. Nematophagous fungi (Orbiliales) capturing, destroying and feeding on the histotrophic larvae of Haemonchus contortus (Nematoda: Trichostrongylidae). Rev. Mex. Micol. 33: 29-35.

Morgan, M., J.M. Behnke, J.A. Lucas and J.F. Peberdy. 1997. In vitro assessment of the influence of 
nutrition, temperature and larval density on trapping of the infective larvae of Heligmosomoides polygyrus by Arthrobotrys oligospora, Duddingtonia flagrans and Monacrosporium megalosporum. Parasitol. 115(3): 303-310. https://doi. org/10.1017/S0031182097001297

Nozdrin, G.A. and A.I. Shevchenko. 2006. Probiotiki na osnove Bacilus subtilis i kachestvo produktsii ptitsevodstva (Probiotics based on Bacilus subtilis, and the quality of the products of poultry breeding). News NSAU. 5: 34-35.

Nozdrin, G.A., A.I. Shevchenko, S.A. Shevchenko, A.A. Lelyak and A.G. Nozdrin. 2017. Fiziologicheskii status i produktivnost gusei pri primenenii probiotikov: monografiya (The physiological status and the productivity of geese with the use of probiotics: monograph). Novosib. State Agrarian University, Gorno-Altaysk State University. IC of NSAU “Zolotoy Kolos”, Novosibirsk.

Perez, D., B. Muñoz, J. Toral, M.Á., Zebadúa, J.L. López, M.E. García, P. de Gives. 2017. Using Duddingtonia flagrans in calves under an organic milk farm production system in the Mexican tropics. Exp. Parasitol. 175: 74-78. https://doi. org/10.1016/j.exppara.2017.02.009

Pyshmantseva, N.A., N.P. Kovekhova and V.A. Sovosko.2011.Probiotiki povyshayut rentabelnost ptitsevodstva (Probiotics increase the profitability of poultry breeding). Poult. Breed. 2: 36-38.

RF patent No. 2253671. 1998. Shtamm griba duddingtonia flagrans, proyavlyayushchii svoistva protiv gallovykh nematod rastenii i paraziticheskikh nematod zhivotnykh i stimuliruyushchii rost i razvitie rastenii [Strain of fungus duddingtonia flagrans exhibiting the properties against root-knot nematodes in plants and parasitic nematodes in animals, and stimulating the growth and development of plants]. Patent of Russia No. 2253671. Bull. No. 33.

RF patent No. 2634390 S1. 2016. Stamm nematofagovogo griba Arthrobotrys oligospora, porazhayuschiy yaitsa I lichinki tsistoobrazuyuschey zolotistoy kartofelnoy nematody Globodera rostochiensis $\mathrm{v}$ tsistah (The strain of the nematophagous fungus Arthrobotrys oligospora, affecting the eggs and larvae of the cyst-forming golden potato nematode Globodera rostochiensis in cysts). Patent of Russia No. 2634390.

Salkova, D., M. Panayotova-Pencheva, S. Movsesian,
S. Beer, M. Voronin and I. Arkhipov. 2014. A1ternativnye metody borby s parazitarnymi boleznyami u zhivotnykh (Alternative methods of combating parasitic diseases in animals). Russ. Parasitol. Mag. 1: 93-103.

Santos, C.P., T. Padilha and M.L.A. Rodrigues. 2001. Predatory activity of Arthrobotrys oligospora and Duddingtonia flagrans on pre-parasitic larval stages of cyathostominae under different constant temperatures. Ciência Rural. 31(5): 839-842. https://doi.org/10.1590/S010384782001000500016

Shkolnikov, E.E, I.V. Pavlenko, L.A. Neminuschaya, T.A. Skotnikova, E.F. Tokarik, I.V. Bobrovskaya, D.N. Filimonov, V.V. Gavrilov, I.V. Kovalsky, Z.A. Kanarskaya and I.A. Khusainov. 2014. Ekobiotekhnologicheskie preparaty dlya agropromyshlennogo kompleksa Rossii (Ecobiotechnological preparations for the agro-industrial complex of Russia). News Kazan Technol. Univ. 13: 255-263.

Teplyakova, T.V., 1999. Bioecologicheskiye aspekty izucheniya I ispolzovaniya hischnyh gribov-gifomitsetov (Bioecological aspects of the study and use of hyphomycete predatory fungi). Novosibirsk.

Teplyakova, T.V., 2018. Grib, porazhayuschiy yaytsa I lichinki tsistoobrazuyuschey zolotistoy kartofelnoy nematody (A fungus that infects eggs and larvae of a cyst-forming golden potato nematode). Zaschita I Karantin Rasteniy. 11: 20-21.

Uchasov, D.S., D.S. Okasov, V.S. Buyarov and N.I. Yarovan 2014. Probiotiki i prebiotiki v promyshlennom svinovodstve i ptitsevodstve: monogr. [Probiotics and prebiotics in industrial pig and poultry breeding: a monograph]. Publishing house of the Orel SAU, Orel. pp. 7-22.

Wang, W., Q. Meng and J. Qiao 2014. Isolation of Arthrobotrys oligospora from soil of the Chinese Northern Tianshan Mountain slope pasture show predatory ability against Haemonchus contortus larvae. Biocontrol Sci. Technol. 24(2): 170-179. https://doi.org/10.1080/09583157.2013.853727

Wang, Y., L. Sun and S. Yi 2013. Naturally occurring nanoparticles from arthrobotrys oligospora as a potential immunostimulatory and antitumor agent. Adv. Funct. Mater. 23: 2175-2184. https:// doi.org/10.1002/adfm.201202619 